Journal of Research in Nursing

Vol. 1, No. 1, 2015

Print ISSN 2244-2723

University of Cebu

Cebu City, Cebu, Philippines

\title{
Maritime Students' Knowledge on Sexually Transmitted Infections
}

\author{
Helen Mae O. Pogoy \\ Mauro Allan P. Amparado
}

\section{Abstract}

The study determined the maritime students' knowledge on sexually transmitted infections (STIs) in the University of Cebu Maritime Education and Training Center, Cebu City, Cebu, Philippines, Summer 2011. The findings served as bases for a proposed action plan. This study aimed to answer the questions: (1) what is the profile of the respondents in terms of age, year level, civil status, type of high school education, socio-economic status, place of origin, and sources of information on STIs; (2) what is the respondents' level of knowledge on sexually transmitted infections in terms of basic knowledge on STIs, mode of transmission, sexual practices, and prevention; (3) is there a significant relationship between the respondents' profile and their level of knowledge on STIs; (4) based on the findings of the study, what action plan may be proposed.

This study utilized the descriptive-correlational design using a researcher-made questionnaire. The respondents of the study were 177 maritime students of the University of Cebu Maritime Education and Training Center. The responses of the study were subjected to statistical treatment with the use of frequencies, simple percentage and chi-square Test of Independence. 
Majority of the respondents were 19-21 years old, single, third year level, who graduated from a private high school, with family income of less than 5,000 Philippine pesos, and are residents of Cebu City. They cited friends as the main source of information about STIs. The respondents' level of knowledge on STIs was satisfactory. Their knowledge on the mode of transmission, sexual practices, and prevention was fair. There were significant relationships between the respondents' profile variables and level of knowledge on STIs.

Recommended citation: Pogoy, H. M. O. \& Amparado, M. A. P. (2015). Maritime Students' Knowledge on Sexually Transmitted Infections. Journal of Research in Nursing, 1(1), 50-59. 